\title{
A ressignificação da imagem da criança: uma análise bakhtiniana do vídeo Nuestro México del Futuro
}

\author{
Adail Ubirajara Sobral ${ }^{1}$ \\ Fernanda Taís Brignol Guimarães ${ }^{2}$
}

\section{Resumo}

Investigamos neste estudo como se articulam e se manifestam relações dialógicas no discurso de um vídeo institucional mexicano, produzido em 2012, que causou polêmica ao mostrar crianças vivenciando ficcionalmente situações condenáveis, em diálogo com muitas notícias sobre a violência no México e, assim, criando novos sentidos. Partimos dos pressupostos da Análise Dialógica do Discurso e de alguns conceitos de Bakhtin, principalmente o conceito de arquitetônica, e o de interdiscursividade. Os resultados apontam um processo de ressignificação da imagem da criança como ponto-chave do discurso de apelo do vídeo, bem como um discurso de denúncia com relação à situação do país.

Palavras-chave: Ressignificação; Arquitetônica; Interdiscursividade

\begin{abstract}
:
We investigated in this study how dialogical relationships are articulated and manifested in the discourse of a Mexican institutional video produced in 2012 which was controversial because of showing children fictionally living condemnable situations, dialoguing with a great many news about violence in Mexico and thereby creating new senses. We take as our basis some postulates of Dialogical Discourse Analysis and concepts by Bakhtin, especially those of architectonics and interdiscursivity. Results show a process of resignification of children's image as a key point both for the video's appealing discourse and for its denouncing discourse related to Mexico's situation regarding violence.
\end{abstract}

Keywords: Resignification; Architectonics; Interdiscursivity

\section{Introdução}

A relevância do estudo do vídeo Nuestro México del Futuro ${ }^{3}$ consiste em mostrar de que maneira, a partir da análise do contexto sócio-histórico de produção e

\footnotetext{
${ }^{1}$ Doutor em Linguística Aplicada e Estudos da Linguagem, professor do Programa de Pós-Graduação em Letras da Universidade Católica de Pelotas - UCPEL (Coordenador do LEAL- Laboratório de Estudos Avançados de Linguagens), Pelotas, Rio Grande do Sul, Brasil;adail.sobral@gmail.com

2 Mestranda em Linguística Aplicada pelo Programa de Pós-Graduação em Letras da Universidade Católica de Pelotas - UCPEL (Membro do LEAL.), Pelotas, Rio Grande do Sul, Brasil; CAPES; fernandabage@hotmail.com

${ }^{3}$ Vídeo institucional disponível em: http://www.youtube.com/watch?v=DBt4CDVGZ6Q. Acesso em 24/07/2014.
} 
circulação dos objetos, pode-se melhor verificar como se organizou sua arquitetônica, seu modo específico de organização do dizer e, assim, descrever e analisar com mais propriedade seus modos de instauração de sentido. O conceito de arquitetônica, fundando nos princípios da Análise Dialógica do Discurso - ADD, permite examinar um objeto verbo-visual a partir dessa concepção, que não se ocupou especificamente disso, e o faz de um modo que é compatível com os parâmetros das várias propostas que constituem a ADD.

Partindo, portanto, dos conceitos de arquitetônica e de interdiscursividade, bem como da análise da produção, circulação e recepção do vídeo que é nosso objeto, o trabalho pretende verificar quais as relações dialógicas presentes no objeto e como essas relações ocorrem, a par de mostrar como o verbal e o visual, integrados arquitetonicamente, criam sentidos, em nosso caso, sentidos para além da enunciação originária, diretamente incidentes sobre a realidade do país em que se produziu o vídeo, o México, mas com repercussões em outros lugares.

\section{O interlocutor como parte integrante da enunciação}

Para Bakhtin, a linguagem se constitui como um fenômeno social, sendo o uso que o sujeito faz da língua uma prática social e situada, ou seja, pela ótica dessa concepção teórica, a essência da linguagem é a comunicação discursiva (MARCHEZAN, 2006). Segundo Flores e Teixeira (2005, p. 54), "Bakhtin introduz a ideia de comunicação dialógica, dizendo que a linguagem vive na comunicação dialógica daqueles que a usam.”. Somente através da interação entre os sujeitos situados em dado contexto social e histórico é que os sentidos podem ser construídos, jamais de forma individual.

Segundo essa tradição teórica, o sujeito é concebido como um sujeito discursivo, ao passo que esse sujeito se constitui na presença do outro, através do embate de discursos sociais, isto é, através da interação discursiva com outros sujeitos, estando ambos situados em determinado contexto de interação social. Nas palavras de Sobral (2013, p. 22), "Só me torno eu entre outros eus. Mas o sujeito, ainda que se defina a partir do outro, ao mesmo tempo o define, é o 'outro' do outro: eis o não acabamento constitutivo do Ser". Sobral destaca ainda que:

Revista Leitura V.1 no 55 - jan/jun 2015 - Número temático: Estudos em perspectivas dialógicas. A ressignificação da imagem da criança: uma análise bakhtiniana do vídeo Nuestro México del Futuro. Adail Ubirajara Sobral e Fernanda Taís Brignol Guimarães - p. 98 - 114. 
(...) a proposta do Círculo de não considerar os sujeitos apenas como seres biológicos, nem apenas como seres empíricos, implica ter sempre em vista a situação social e histórica concreta do sujeito, tanto em termos de atos não discursivos como em sua transfiguração discursiva, sua construção em texto/discurso (SOBRAL, 2013, p. 23).

Conforme Bakhtin/Volochinov, "Qualquer que seja o aspecto da expressãoenunciação considerado, ele será determinado pelas condições reais da enunciação em questão, isto é, antes de tudo pela situação social mais imediata" (BAKHTIN/VOLOCHINOV, 2014, p. 116 [grifos no original]).

Assim, a interação discursiva empreendida entre os sujeitos será sempre construída de forma dialógica, bem como sua identidade, que se constitui num processo de intersubjetividade, ou seja, através de um processo relacional de interação com o outro. Quanto às relações dialógicas constitutivas de todo discurso, podemos dizer que para que algo faça sentido é necessário que já faça sentido anteriormente, ou seja, ao enunciar, o sujeito traz em seu discurso a presença de vários outros discursos que circulam na sociedade da qual faz parte, quer se dirija ou não a eles e quer essa presença seja interdiscursiva ou apenas intertextual.

A enunciação, portanto, caracteriza-se como uma arena de vozes sociais, em que há o embate de dizeres, tanto na forma de atualização de discursos passados, quanto na forma de antecipação de uma resposta para discursos futuros, constituindo, assim, o que Bakhtin chama de interdiscurso. Dessa forma, o discurso do sujeito será sempre perpassado por diversos outros discursos.

O locutor, ao produzir um enunciado, pressupõe vários outros enunciados, que estão por trás de sua argumentação, o que implica dizer que toda palavra empregada em dada situação de enunciação vem "carregada de um conteúdo ou de um sentido ideológico ou vivencial" (BAKHTIN/VOLOCHINOV, 2014, p. 99), conforme Flores e Teixeira (2005, p. 48-49), “a palavra (...) em estado de dicionário não é uma realidade da qual o falante se vale para os seus propósitos comunicacionais”. Quanto a isso, Bakhtin/Volochinov (2014, p. 99) diz que "Na realidade, não são palavras o que pronunciamos ou escutamos, mas verdades ou mentiras, coisas boas ou más, importantes ou triviais, agradáveis ou desagradáveis, etc.”.

Revista Leitura V.1 no 55 - jan/jun 2015 - Número temático: Estudos em perspectivas dialógicas. A ressignificação da imagem da criança: uma análise bakhtiniana do vídeo Nuestro México del Futuro. Adail Ubirajara Sobral e Fernanda Taís Brignol Guimarães - p. 98 - 114. 
Nesse sentido, a enunciação constitui-se de um jogo discursivo, em que participam ativa e responsivamente locutor e interlocutor, no sentido de que pontuam, argumentam, completam, tomando determinada posição frente aos enunciados um do outro. Nessa rede de interlocução, que se forma através de enunciados únicos e irrepetíveis não há um enunciado universal, o que significa dizer que todo enunciado é endereçado e pressupõe a presença de, pelo menos, um locutor, um interlocutor e uma situação de enunciação. A partir desses três elementos-chave indispensáveis em toda enunciação, podemos afirmar que, ao enunciar, o locutor sempre endereça o dito a alguém, seu interlocutor real ou presumido, a quem o discurso é dirigido. Como diz Bakhtin/Volochinov,

(...) a enunciação é o produto da interação de dois indivíduos socialmente organizados e, mesmo que não haja um interlocutor real, este pode ser substituído pelo representante médio do grupo social ao qual pertence o locutor. A palavra dirige-se a um interlocutor: ela é função da pessoa desse interlocutor: variará se se tratar de uma pessoa do mesmo grupo social ou não, se esta for inferior ou superior na hierarquia social, se estiver ligada ao locutor por laços sociais mais ou menos estreitos (pai, mãe, marido, etc.). (BAKHTIN/VOLOCHINOV, 2014, p. 116 [grifos no original]).

Dito de outra forma, todo discurso atende a determinado propósito de comunicação e, para tanto, mobiliza determinado projeto comunicativo. Este último envolve uma forma composicional - ligada à materialidade do texto - e uma forma arquitetônica - ligada à superfície discursiva, que organiza o dizer (SOBRAL; GELETKANICZ, 2013). Estando o discurso sempre ligado a determinado projeto de dizer, ele irá mobilizar dada forma arquitetônica, a qual se constitui da interrelação existente entre autor, ouvinte e tópico. Adentramos aqui no conceito de valoração do discurso, conceito este que diz respeito ao julgamento de valor que permeia toda a situação de interação discursiva. Todo enunciado possui acento apreciativo, o que implica dizer que nosso discurso é sempre moldado pela valoração ativa de nosso interlocutor presumido, a quem esse discurso se dirige.

\section{O vídeo institucional Nuestro México del Futuro: uma descrição}

Revista Leitura V.1 no 55 - jan/jun 2015 - Número temático: Estudos em perspectivas dialógicas. A ressignificação da imagem da criança: uma análise bakhtiniana do vídeo Nuestro México del Futuro. Adail Ubirajara Sobral e Fernanda Taís Brignol Guimarães - p. 98 - 114. 
Nosso objeto de análise recai sobre um vídeo institucional mexicano, de responsabilidade do movimento social Nuestro México del Futuro, exibido no ano de 2012 - ano eleitoral - que causou grande polêmica no México e no mundo ao mostrar crianças desempenhando o papel de adultos e vivenciando situações de extrema violência. As crianças vivem o papel de empresários, donas de casa, repórteres, além de aparecerem protagonizando assaltos, sequestros, tráfico de pessoas, entre outras ações condenáveis.

O vídeo inicia mostrando uma manhã normal de trabalho, com uma diferença, quem desperta para enfrentar sua rotina de trabalho não é um adulto, mas um menino de aproximadamente 10 anos de idade. O menino levanta da cama vestindo roupas íntimas e apresenta uma expressão de cansaço e tédio em seu rosto. Na cama, alguém permanece deitado, provavelmente uma menina que desempenha o papel de uma possível esposa. Sentado à mesa do café da manhã, o menino lê o jornal enquanto fuma seu cigarro. As notícias no jornal e no noticiário da TV não são nada boas.

O jornal intitulado El Soberano, que o menino lê enquanto toma seu café, traz a seguinte chamada estampada na primeira página: Alarmante aumento de la violencia en el país ${ }^{4}$. Já no noticiário da TV, uma menina que vive o papel de âncora do telejornal informa que se trata de mais um dia de contingência ambiental e que as pessoas que pretendem sair à rua devem usar máscaras para evitar inalação de ar poluído. A menina informa, ainda, que estão canceladas as aulas de Educação Física, bem como os recreios nas escolas.

No momento em que o menino deposita seu cigarro no cinzeiro, sobre a mesa, é possível visualizarmos vários outros cigarros já ali depositados, o que demonstra quantitativamente seu nível de dependência com relação ao cigarro, podendo indicar sinais de stress e ansiedade já pela manhã. As roupas e o cabelo do menino remetem ao imaginário que temos de um empresário, um advogado, ou algo do tipo, pois ele veste terno e gravata e usa gel no cabelo, além de portar uma pasta preta, que serve, provavelmente, para transportar documentos.

Ao sair de casa, o menino é abordado por dois outros meninos que o assaltam e o obrigam a entregar o que tem sob a ameaça de uma arma apontada para sua cabeça. Neste momento, começa a tocar ao fundo uma música tranquila que fala de uma

\footnotetext{
${ }^{4}$ Alarmante aumento da violência no país. Tradução nossa.

Revista Leitura V.1 no 55 - jan/jun 2015 - Número temático: Estudos em perspectivas dialógicas. A ressignificação da imagem da criança: uma análise bakhtiniana do vídeo Nuestro México del Futuro. Adail Ubirajara Sobral e Fernanda Taís Brignol Guimarães - p. 98 - 114.
} 
manhã linda e a compara, de forma metafórica, a uma flor. Os meninos que praticam o assalto correm pela rua e a câmera os acompanha revelando um cartaz em que aparece uma foto de outro menino, aparentemente, no papel de um político, já que ao lado de sua foto estampada de terno e gravata, observamos o seguinte enunciado: Yo sí cumplo ${ }^{5}$. E, logo abaixo do enunciado, aparece um nome, provavelmente o seu. A forma composicional do cartaz remete a um típico cartaz de propaganda de candidatos a algum cargo político. Percebemos sobre a foto desse suposto candidato uma faixa branca com a palavra clausurado em letras garrafais.

$\mathrm{Na}$ cena seguinte, outro menino vive o papel de um policial corrupto para quem os assaltantes pagam propina. A corrupção continua sendo retratada pelos pequenos atores na cena em que aparecem dois meninos em uma sala de escritório. Um dos meninos entrega ao outro uma significativa quantia em dinheiro. $\mathrm{O}$ dinheiro é posto em uma mala preta e coberto com um jornal, que traz a seguinte chamada: México no crece lo que puede ${ }^{6}$. Nessa sala, percebemos uma televisão que mostra um dos meninos da cena - o que recebe o dinheiro - vestindo terno e gravata, cochilando, em meio às palavras En vivo ${ }^{7}$ (no canto superior esquerdo) e sesión extraordinaria ${ }^{8}$ (no canto inferior direito).

Enquanto isso nas ruas o trânsito é caótico, crianças vivem o papel de uma população em fúria, em que as pessoas se insultam, discutem, se agridem verbalmente. $\mathrm{O}$ ar apresenta um aspecto cinzento, como o de uma fumaça. Há protestos em que crianças vivem o papel de pessoas desesperadas que clamam por seus direitos e portam cartazes com dizeres de indignação, como por exemplo: Yá basta e No a la corupcion? A tropa de choque, formada também por crianças, tenta conter o caos e entra em confronto com os manifestantes.

A próxima cena mostra um menino pedindo esmola e sendo ignorado por quem passa. E, do alto dos edifícios, outros meninos observam a situação caótica em que a cidade se encontra e demonstram expressões de desapontamento em seus rostos. A violência continua sendo representada em uma cena de sequestro, em que uma

\footnotetext{
${ }^{5}$ Eu sim cumpro. Tradução nossa.

${ }^{6}$ México não cresce o quanto pode. Tradução nossa.

${ }^{7}$ Ao vivo. Tradução nossa.

${ }^{8}$ Sessão extraordinária. Tradução nossa.

${ }^{9}$ Já basta e Não à corrupção. Tradução nossa.
}

Revista Leitura V.1 no 55 - jan/jun 2015 - Número temático: Estudos em perspectivas dialógicas. A ressignificação da imagem da criança: uma análise bakhtiniana do vídeo Nuestro México del Futuro. Adail Ubirajara Sobral e Fernanda Taís Brignol Guimarães - p. 98 - 114. 
gangue (de meninos), portando armas, aborda sua vítima na rua e a joga dentro do porta-malas de um carro.

O tráfico de pessoas também é retratado no vídeo. Na fronteira entre México e Estados Unidos, um coiote - como são denominados os encarregados de atravessar mexicanos para o trabalho ilegal nos Estados Unidos - aparece transportando vários mexicanos em um pequeno caminhão, quando é abordado pela polícia (novamente todos representados por crianças na faixa etária de, aproximadamente, dez anos de idade).

Na sequência, o vídeo mostra duas meninas que passeiam pela rua, passando por muros com vários rostos de pessoas desaparecidas e de repente as duas são surpreendidas por um tiroteio entre policiais e criminosos, em plena luz do dia. Todos saem gritando, tentando se proteger da violência e do caos total que se instala nas ruas. Os policiais prendem os criminosos e os levam para a delegacia. Lá, estes aparecem algemados em meio a flashes fotográficos, tendo a sua frente uma mesa com as armas e o dinheiro apreendido.

O vídeo termina com os bandidos sendo conduzidos para suas celas carcerárias. Neste momento, uma menina aparece falando que se esse for o futuro que a espera ela não o quer. A menina rechaça a atitude dos políticos ao trabalharem somente para seus partidos e não para o povo. $\mathrm{O}$ vídeo se encerra com a menina fazendo um chamamento, ocasião em que ela menciona quatro nomes de pessoas, as quais, mais tarde, constatamos serem os nomes dos candidatos à presidência do México naquele ano.

\section{O vídeo institucional Nuestro México del Futuro: uma análise}

\section{A ressignificação como ponto-chave do discurso de apelo do vídeo}

Sabemos que o olhar do analista que pretende seguir os preceitos da teoria de Bakhtin não deve recair apenas sobre o objeto de análise, desconsiderando o contexto de enunciação no qual o discurso foi produzido e no qual ele circula. Tomando por base o conceito de forma arquitetônica, que, nas palavras de Sobral (2009, p. 107-108), envolve "dialeticamente forma, conteúdo e material, em sua interdependência", pretendemos refletir sobre as relações existentes entre o contexto sócio-histórico de vídeo Nuestro México del Futuro. Adail Ubirajara Sobral e Fernanda Taís Brignol Guimarães - p. 98 - 114. 
produção e circulação do vídeo institucional mexicano e sua forma composicional e arquitetônica. Pensar no contexto implica pensar também na recepção ativa do interlocutor do discurso, isto é, todo discurso tem um tom, uma valoração que aproxima locutor e interlocutor, trazendo este último para a superfície discursiva. Essa relação entre entoação avaliativa e recepção ativa mostra que todo discurso é endereçado e, através dos presumidos, faz emergir em sua superfície um embate de vozes, de posições, de ideologias, em que participam ativamente locutor e interlocutor.

Nossa pesquisa, realizada na internet, revelou que o vídeo institucional Nuestro México del Futuro é produto de um movimento social sem precedentes a nível nacional que convidou a todos os mexicanos para que expressassem suas opiniões sobre o México em que gostariam de viver. Este movimento construído pelos mexicanos conseguiu reunir milhões de opiniões, que foram compiladas no livro El Decreto de Nuestro México del Futuro, o único livro escrito por milhões de mexicanos em busca de uma mudança nos rumos do país. As crianças que atuaram no vídeo entregaram o livro aos candidatos à presidência, no ano de 2012, que o assinaram como forma de mostrarem-se cientes das reivindicações dos mexicanos e de comprometerem-se com a tão desejada mudança nos rumos do México, caso venham a governar o país ${ }^{10}$.

Os elementos composicionais do vídeo aliados a fatores que dizem respeito ao contexto e à recepção ativa revelam uma arquitetônica que traz uma forma atípica de discurso, já que, ao contrário do que estamos acostumados a ver, ou seja, a violência representada por adultos, o que, de certa forma, já está tão naturalizado que não nos choca mais, o vídeo apresenta atores infantis em sua constituição. Essa forma atípica do discurso é materializada através do processo de ressignificação da imagem da criança, que está naturalmente ligada à inocência, à pureza. Essa imagem é retirada de seu contexto para significar em outro contexto.

Dessa forma, a ressignificação da imagem da criança constitui o pontochave do discurso examinado porque é por meio dela que conseguimos apreender a valoração ou recepção ativa, em que o locutor usa a resposta presumida do interlocutor e antecipa-se a ela em sua argumentação. Assim, o ato de produzir um vídeo em que

\footnotetext{
${ }^{10}$ Informações disponíveis em: http://www.nuestromexicodelfuturo.com.mx/crear\#sthash.30Meli8g.dpuf. Acesso em: 24/07/2014.

Revista Leitura V.1 no 55 - jan/jun 2015 - Número temático: Estudos em perspectivas dialógicas. A ressignificação da imagem da criança: uma análise bakhtiniana do vídeo Nuestro México del Futuro. Adail Ubirajara Sobral e Fernanda Taís Brignol Guimarães - p. 98 - 114.
} 
atuassem adultos ao invés de crianças não teria o mesmo efeito e, por não significar da mesma forma, provavelmente o vídeo não assumiria as proporções que assumiu.

Desse modo, a forma atípica que emerge da arquitetônica do vídeo, que chamamos aqui de ressignificação da imagem da criança, funciona mediante o efeito de choque que provoca no interlocutor, como uma forma de chamar a atenção das pessoas para a situação de extrema violência e descaso em que se encontra o México. Percebemos a antecipação do interlocutor, que ocorre através da valoração do dizer, ou seja, presume-se que a questão da violência já está tão naturalizada que se fosse feito um vídeo com a atuação de adultos a população não daria a atenção pretendida para o apelo, e, em resposta a isso, usam-se atores crianças exercendo papeis não costumeiramente associados a crianças.

A atuação de crianças revela ainda um discurso de denuncia: essas crianças poderão ser os protagonistas da violência no futuro se a situação do país não mudar. $\mathrm{O}$ discurso do vídeo é mobilizado de forma antagônica e paradoxal, já que contrapõe inocência e criminalidade, pondo em cena um jogo discursivo que serve como um apelo para o fim da violência, na forma de denuncia para o fato de que a inocência das crianças será corrompida no futuro se elas continuarem presenciando e convivendo com esse tipo de comportamento dos adultos. A forma antagônica de constituição do discurso do vídeo revela-se, ainda, na escolha da música tranquila, que fala de uma manhã linda, o que é totalmente o oposto à manhã mostrada no vídeo, em que opera o caos. Observa-se que as cenas de violência e esse fundo musical tranquilo estão arquitetonicamente integrados no todo do discurso, sendo, per se, opostos entre si; a oposição serve precisamente para melhor realizar o projeto enunciativo do locutor. A música e a inocência infantil são negadas pelas cenas de violência de que elas são protagonistas ao realizar ações adultas condenáveis, e o vídeo cria com isso o sentido de que essa negação será a única realidade das crianças mais tarde caso a situação denunciada permaneça.

O fato de o vídeo apresentar crianças em sua composição também remete discursivamente ao próprio nome do movimento social, Nuestro México del Futuro, já que a palavra criança vem carregada ideologicamente com termos como esperança, renovação, enfim uma nova oportunidade de fazer diferente, de apostar em um futuro melhor para o mundo. Ideologicamente, criança é igual a futuro, e a condição de ser 
criança está ligada a uma nova chance de se reinventar, de mudar a realidade atual e criar algo totalmente novo para o mundo e para as pessoas. Dessa forma, a atuação das crianças dialoga diretamente com a questão do futuro, pois é comum que, ao pensarmos em crianças, pensemos em questões ligadas ao futuro. O ser criança nos remete, naturalmente, à esperança de um porvir.

Através dos elementos composicionais do vídeo como as roupas utilizadas e o cabelo dos personagens, o interlocutor é direcionado a possíveis interpretações com relação ao tipo de profissão ou posição social assumida pelos personagens: político, advogado, donas de casa etc. Da mesma forma, as atitudes e expressões faciais e/ou corporais denotam stress, cansaço, desânimo, tédio etc., todos vinculados a esses papeis sociais. Do mesmo modo, as notícias dos jornais e da TV, que falam de violência, poluição, corrupção, assim como os cartazes nas ruas, o trânsito caótico, o ar cinzento tudo isso serve ao mesmo projeto comunicativo, que denuncia a situação negativa do México, tanto no âmbito da natureza - revelada através da poluição - quanto no âmbito social - desorganização, caos, corrupção, violência -, e também no âmbito emocional stress, tédio, desanimo.

As escolhas discursivas, como as péssimas notícias estampadas nos jornais que aparecem no vídeo - tanto na hora em que o menino aparece lendo o jornal no café da manhã, como quando o jornal é utilizado para cobrir o dinheiro na sala de escritório, servindo aí de pretexto para que o interlocutor perceba novamente a presença de notícias ruins estampadas nos jornais - ou então as notícias de mesmo teor que são anunciadas no noticiário da TV, ou ainda a quantidade significativa de cigarros já fumados durante o café da manhã, todas essas escolhas não estão ali por acaso, mas funcionam como elementos discursivos que servem a um mesmo projeto comunicativo, de apelo, de denuncia, de reivindicação.

Percebemos em várias passagens do vídeo uma forte posição avaliativa de crítica aos políticos, como no caso do cartaz em que aparece a foto de um possível candidato acompanhada do enunciado yo sí cumplo (o que remete às promessas dos candidatos em época de eleição, em geral não cumpridas) e da palavra clausurado (que remete a prisão). Outra passagem que, provavelmente, é uma crítica a políticos corruptos consiste na cena em que aparece um menino em um escritório, gabinete, ou coisa parecida, recebendo propina de outro. O menino que recebe o dinheiro aparece 
logo em seguida na televisão da sala cochilando em meio às palavras en vivo (ao vivo) e sesión extraordinaria (sessão extraordinária), o que remete ao descaso dos políticos para com o povo.

Nossa pesquisa sobre o vídeo institucional, realizada na internet, nos revelou também várias reportagens sobre a onda de violência, sequestros e tráfico de drogas que vem ocorrendo no México já há algum tempo, dentre as quais destacamos a seguinte, que tem relações interdiscursivas com o vídeo: Violência faz cidade do México perder imagem de oásis de segurança ${ }^{11}$, a qual analisaremos a seguir.

\title{
A reportagem: Uma análise dos aspectos contextuais
}

\author{
Violência faz Cidade do México perder imagem de oásis de segurança
}

Alberto Nájar

Da BBC Mundo na Cidade do México

27 dezembro 2013

Por anos da guerra contra o narcotráfico, grande parte das cidades no México tiveram constantes conflitos armados, explosões de bombas e aparições de dezenas de cadáveres nas ruas. Mas no período de 2007 a 2011, a capital do país se manteve relativamente isolada da guerra.Agora este "oásis" parece estar desaparecendo. Nos últimos meses, a Cidade do México registrou o sequestro e execução de 13 jovens, o assassinato de adolescentes e uma disputa de gangues pelo controle do mercado de drogas.Especialistas e ONGs dizem que o crescimento da violência é reflexo da atuação de novos grupos criminosos no Distrito Federal mexicano que eram relativamente desconhecidos até recentemente.As autoridades rejeitam esse argumento. "Na Cidade do México o crime organizado não opera", diz o procurador da Justiça Rodolfo Ríos.Mas para alguns cidadãos, há uma crescente sensação de insegurança."Havia uma época, há uns quatro anos, em que a Cidade do México era vista como segura, mas agora já não é mais", disse à BBC María Elena Morera, presidente da organização Causa en Común, entidade que luta por direitos civis. "Estamos arriscando perder um espaço em que nos sentíamos bastante seguros", diz.

\section{Caso Heaven}

Um dos casos que mais despertou preocupações foi o sequestro e execução de 13 jovens no Bar Heaven, que fica em uma das principais regiões turísticas da capital, a Zona Rosa. $\mathrm{O}$ ato teria sido uma vingança

\footnotetext{
${ }^{11}$ Disponível em: http://www.bbc.co.uk/portuguese/noticias/2013/12/131227_mexico_violencia_dg.shtml. Acesso em: 24/07/2014.

Revista Leitura V.1 no 55 - jan/jun 2015 - Número temático: Estudos em perspectivas dialógicas. A ressignificação da imagem da criança: uma análise bakhtiniana do vídeo Nuestro México del Futuro. Adail Ubirajara Sobral e Fernanda Taís Brignol Guimarães - p. 98 - 114.
} 
de traficantes contra um grupo rival, diz a procuradoria geral da Justiça do Distrito Federal.Os jovens apareceram mortos meses depois em uma vala. As investigações estabeleceram que policiais participaram do sequestro.O caso do Bar Heaven também provocou divergências políticas entre o governo federal e a prefeitura da Cidade do México. O comissário nacional de Segurança, Manuel Mondragón, diz que gangues de narcotráfico atuam na capital, mas o prefeito, Miguel Mancera, nega.

A sensação de insegurança aumentou. Uma pesquisa recente no jornal Reforma mostrou que $49 \%$ dos entrevistados acreditam que o Distrito Federal é menos seguro do que outras cidades do país, enquanto para outros $29 \%$ a violência aumentou no último ano.As autoridades afirmam que se trata meramente de uma percepção popular, já que as estatísticas oficiais indicam que houve uma queda de $12,4 \%$ nos índices de criminalidade.A população duvida dos números oficiais e toma precauções."Em dezembro não vamos sair de férias. Sempre passamos o Ano Novo em Acapulco, mas agora os ladrões não nos deram permissão", disse Angélica Zuñiga, que mora no bairro Mixcoac, no sul da capital mexicana.Para a presidente da ONG Causa en Común, as estatísticas oficiais de crimes podem ser baixas porque muitas pessoas não estariam registrando ocorrências.A prefeitura da Cidade do México lançou uma nova estratégia de segurança para tentar reconquistar a confiança dos cidadãos. Foram criados gabinetes de segurança nas 16 microrregiões da capital, que deverão elaborar relatórios diários sobre os registros de crimes nas suas áreas."Os números são positivos, mas precisamos também combater a percepção conhecida como insegurança objetiva", diz Mancera. "É algo que precisa ser conquistado a cada dia", afirma.

\section{Figura $1^{12}$}

A reportagem apresentada na Fig. 1 mostra a situação em que se encontrava o México quando o movimento social Nuestro México del Futuro mobilizou milhões de mexicanos para dar um basta. Ao analisar o contexto de produção e circulação do vídeo mexicano, percebemos que ele retratou perfeitamente a situação do país, naquele momento, não jornalisticamente, mas de modo esteticamente dramático, como vimos dizendo.

Percebe-se que, de 2007 a 2011, apenas a Cidade do México era considerada segura no país, mas que esse quadro mudou também na capital, com a disputa de gangues pelo controle do narcotráfico, que culminou no sequestro e execução de 13 jovens no bar Heaven. Vejamos o seguinte trecho retirado da reportagem acima: Por anos da guerra contra o narcotráfico, grande parte das cidades no México tiveram constantes conflitos armados, explosões de bombas e aparições de dezenas de cadáveres nas ruas. Mas no período de 2007 a 2011, a capital do país se manteve relativamente isolada da guerra.

A reportagem revela a situação dos mexicanos que sofrem com a ação de gangues nas mais diversas regiões do país, com o tráfico de drogas, com constantes sequestros, com policiais corruptos e com o descaso das autoridades e dos governantes para com a situação de insegurança em que a população se encontra. "Em dezembro não

\footnotetext{
${ }^{12}$ Grifos no original.
}

Revista Leitura V.1 no 55 - jan/jun 2015 - Número temático: Estudos em perspectivas dialógicas. A ressignificação da imagem da criança: uma análise bakhtiniana do vídeo Nuestro México del Futuro. Adail Ubirajara Sobral e Fernanda Taís Brignol Guimarães - p. 98 - 114. 
vamos sair de férias. Sempre passamos o Ano Novo em Acapulco, mas agora os ladrões não nos deram permissão", disse Angélica Zuñiga, que mora no bairro Mixcoac, no sul da capital mexicana.

Enquanto 13 jovens são sequestrados e aparecem mortos em uma vala meses depois, caso em que há, inclusive, a suspeita da participação de policiais, as autoridades afirmam que o aumento da violência na Cidade do México não passa de uma percepção de insegurança pelas pessoas. Conforme o procurador da justiça, "Na Cidade do México o crime organizado não opera".

Considerando o ano de produção e circulação do vídeo, 2012, ano eleitoral, percebemos claramente a crítica feita aos governantes do México. Essa crítica, como já mencionamos, se confirma com o fechamento do vídeo, em que cada candidato à presidência do país é chamado pelo nome. O chamamento dos candidatos pelo nome funciona como forma de firmar um compromisso com o futuro governante do México, para que este se comprometa a mudar seus rumos para melhor.

A seguir, analisamos os comentários que acompanham a publicação do vídeo no Youtube como forma de investigar a reação e recepção das pessoas com relação ao vídeo.

\section{Os comentários: Uma análise da recepção do vídeo}

Com relação à reação e recepção das pessoas para com o vídeo institucional mexicano, percebemos, através dos comentários que acompanham a postagem deste no Youtube, as mais diversas reações: desaprovação, perplexidade, concordância, entre outras. A seguir, analisaremos alguns desses comentários como forma de demonstrar a polêmica causada pela atuação de crianças em cenas adultas condenáveis. Como forma de manter em sigilo a identidade das pessoas nos comentários por nós analisados seus nomes foram substituídos pelas letras A,B,C e D.

Com. A

10 meses atrás

bem mostrado colocando crianças deu mais credibilidade, atenção pois é isso que se tornaram essas crianças atuado pelos atores mirins se tornaram, caso não seja feito nada. Foi lindo bem feito, propaganda

Revista Leitura V.1 no 55 - jan/jun 2015 - Número temático: Estudos em perspectivas dialógicas. A ressignificação da imagem da criança: uma análise bakhtiniana do vídeo Nuestro México del Futuro. Adail Ubirajara Sobral e Fernanda Taís Brignol Guimarães - p. 98 - 114. 
Figura $2^{13}$

$\mathrm{Na}$ Fig.2, percebemos a concordância de A com relação à atuação de crianças nas cenas do vídeo mexicano. Através de seu comentário, A demonstra sua compreensão com relação ao discurso de denuncia do vídeo, o que pode ser apreendido no trecho em que A fala que a atuação de crianças dá maior credibilidade ao que está sendo mostrado e que é isso que as crianças se tornarão se nada for feito, referindo-se às cenas de violência mostradas no vídeo institucional mexicano.

O discurso de aprovação de A para com a atuação de crianças no vídeo é fortemente enfatizado ao final de seu comentário através do uso de aspas e letras em caixa alta na escrita da seguinte frase: "SE NÃO FOR FEITO NADA ISSO QUE ACONTECERA COM NOSSAS CRIANÇAS” e, em seguida, A reforça sua aprovação com a escrita da frase também em caixa alta: LINDO BATO PALMAS LEGAL.

\section{Com. B}

$\underline{5 \text { meses atrás }}$

Que horror cade os pais dessas criançaCom. C5 meses atrás

querem a realidade mais direta que isso... pessoas no face dizendo que horror? horror é fingir que isso não é algo real.Com. D

1 mês atrás

vou explicar pra quem nao entendeu, pq li uns comentarios aqui e ta dificil... o video é uma critica à sociedade mexicana atualmente, mostrando que se algo nao mudar agora, no futuro as crianças vão passar por tudo isso que aparece no vídeo vao sofrer abusos policiais, vao sofrer com politicos corruptos, vao cometer crimes etc etc é uma critica muito boa, tem que se mudar a sociedade agora, pra que isso nao aconteça no futuro.

\section{Figura $3^{14}$}

\footnotetext{
${ }^{13}$ Comentário disponível em: http://www.youtube.com/watch?v=fhAxW1Wsd3o. Acesso em 24/07/2014.

${ }^{14}$ Comentários disponíveis em: http://www.youtube.com/watch?v=yunBLozJipc. Acesso em: 24/07/2014.
}

Revista Leitura V.1 no 55 - jan/jun 2015 - Número temático: Estudos em perspectivas dialógicas. A ressignificação da imagem da criança: uma análise bakhtiniana do vídeo Nuestro México del Futuro. Adail Ubirajara Sobral e Fernanda Taís Brignol Guimarães - p. 98 - 114. 
Na Fig.3, percebemos que B mostra-se perplexo com o que vê. B demonstra total desaprovação para com a atuação de crianças nas cenas de violência mostradas no vídeo mexicano. B pergunta-se, inclusive, pelos pais das crianças, que deixaram que elas fossem expostas em situações condenáveis.

C responde ao comentário de $\mathrm{B}$ e também de algumas pessoas que, conforme ele explicita em seu comentário, estariam expondo opiniões de desaprovação, através de postagens na rede social Facebook, em que se diziam horrorizadas com relação à atuação das crianças no vídeo. $\mathrm{C}$ demonstra não só sua aprovação para com o vídeo, mas, também, sua discordância para com as pessoas que se dizem horrorizadas, sustentando o argumento de que horror mesmo é fingir que a situação não é real.

Por fim, D responde aos comentários anteriores explicando do que realmente trata o vídeo, isto é, de uma crítica à sociedade mexicana. Assim como A, D também salienta sua compreensão com relação ao discurso de denuncia do vídeo mexicano. D sustenta o argumento de que o discurso do vídeo aponta para o fato de que se a sociedade mexicana não mudar, o que está sendo mostrado no vídeo irá acontecer no futuro. As crianças irão vivenciar todas aquelas situações de violência, corrupção, abusos policias etc. representadas nas cenas do vídeo institucional mexicano.

\section{Considerações finais}

Conforme vimos, para fins de análise, não podemos jamais desconsiderar o contexto sócio-histórico do qual o objeto faz parte. Assim, o vídeo institucional mexicano Nuestro México del Futuro se tomado por si só causaria espanto pela forma como constitui-se, através da atuação de crianças em cenas adultas condenáveis. Somente após a análise de seu contexto é que podemos perceber que se tratava de uma crítica à sociedade mexicana e aos governantes do país.

Nossa pesquisa mostrou a situação do México naquele momento, como vimos na análise da reportagem Violência faz cidade do México perder imagem de oásis de segurança, mostrada acima. Além disso, por meio da pesquisa sobre o contexto de produção e circulação do vídeo foi possível constatar que este se constitui como ação de um movimento social, que mobilizou milhares de mexicanos em prol de um México melhor para o futuro.

Revista Leitura V.1 no 55 - jan/jun 2015 - Número temático: Estudos em perspectivas dialógicas. A ressignificação da imagem da criança: uma análise bakhtiniana do vídeo Nuestro México del Futuro. Adail Ubirajara Sobral e Fernanda Taís Brignol Guimarães - p. 98 - 114. 
Como foi possível perceber, o vídeo, oportunamente criado em ano eleitoral, traz ao seu final um chamamento de quatro nomes de pessoas, que, posteriormente, nossa análise mostrou serem os nomes dos candidatos à presidência do México, naquele ano (2012). Além do fato de serem mencionados os nomes dos candidatos ao final do vídeo, a análise do contexto revelou, ainda, a criação do livro El Decreto de Nuestro México del Futuro, o qual continha milhares de assinaturas dos mexicanos que opinaram sobre o México que gostariam de ter no futuro. Cada um dos candidatos recebeu das mãos das crianças que atuaram no vídeo uma cópia do livro, momento em que os candidatos foram convidados a assiná-lo também, como forma de demonstrar comprometimento para com o desejo dos mexicanos por um México melhor no futuro.

Caso analisássemos o vídeo como um enunciado isolado, retirado de seu contexto, não seria possível apreender seu sentido, e nos restringiríamos a uma análise "textual". Podemos ver a comprovação disso considerando alguns comentários analisados, em que as pessoas se mostraram contrárias à atuação de crianças em cenas que envolvem assaltos, sequestros, tráfico de drogas, entre outras. Um dos comentários, inclusive, faz um questionamento sobre onde estariam os pais das crianças que permitiram que elas participassem de um vídeo como esse. O vídeo por si só causou espanto e revolta em algumas das pessoas, porque tomado de maneira literal, mas, analisado em seu contexto, ele revela ser uma forte e expressiva crítica à sociedade mexicana.

Nossos resultados revelaram um discurso de denúncia: essas crianças serão os protagonistas da violência no futuro se a situação do país não mudar. Percebemos que o processo de ressignificação da imagem corriqueira da criança revela-se como ponto-chave do discurso de apelo que emerge da arquitetônica do vídeo institucional mexicano. Através dessa ressiginificação, podemos constatar o ato de valoração ou recepção ativa postulado pela $\mathrm{ADD}$, em que se tem uma antecipação da resposta do interlocutor presumido. Dessa forma, presume-se que se o vídeo fosse constituído através da atuação de adultos, pelo fato de a violência e o descaso das autoridades e dos políticos já estarem tão naturalizados entre as pessoas, seu efeito não seria o mesmo e o apelo não assumiria a proporção que assumiu.

Logo, podemos legitimamente dizer que o fato de o vídeo recorrer em sua arquitetônica à atuação de crianças ao invés de adultos mostra-se como uma antecipação vídeo Nuestro México del Futuro. Adail Ubirajara Sobral e Fernanda Taís Brignol Guimarães - p. 98 - 114. 
pelo locutor da resposta ativa de seu interlocutor real e presumido. Ao recorrer a essa estratégia, o vídeo realiza mais plenamente o projeto enunciativo de seu locutor; desnaturalizando a violência, ao mostrá-la sendo "cometida" por crianças, o vídeo denuncia a banalização da violência, do mal, e mostra comportamentos adultos que estão na base dessa banalização. Seu projeto enunciativo recorre a uma dada arquitetônica com vistas a realizar uma entoação ativa específica que leva em conta as réplicas presumidas dos interlocutores.

\section{Referências}

BAKHTIN, M. Estética da criação verbal. Trad. Paulo Bezerra. São Paulo, SP: Martins Fontes, 2006.

$16^{\mathrm{a}}$ Ed., 2014.

; VOLOCHINOV, V. N. Marxismo e Filosofia da linguagem. São Paulo: Hucitec

FLORES, V. N.; TEIXEIRA, M. Introdução à lingüística da enunciação, São Paulo: Contexto, 2005.

MARCHEZAN, R. C.. Diálogo. In: BRAIT, B. (Org.). Bakhtin: Outros Conceitos-Chave. São Paulo: Contexto, 2006.

SOBRAL, A. Ato / Atividade e evento. In: BRAIT, B. (Org.). Bakhtin: Conceitos-Chave. São Paulo: Contexto $5^{\text {a }}$ Ed., 2013.

; GELETKANICZ, M. F. A arquitetônica de Luna Clara e Apolo Onze: uma reflexão metalinguística. Bakhtiniana: Revista de Estudos do Discurso, v. 8, p. 220-240, 2013.

Revista Leitura V.1 no 55 - jan/jun 2015 - Número temático: Estudos em perspectivas dialógicas. A ressignificação da imagem da criança: uma análise bakhtiniana do vídeo Nuestro México del Futuro. Adail Ubirajara Sobral e Fernanda Taís Brignol Guimarães - p. 98 - 114. 